\title{
Nghiên cứu sự hiện diện của nhóm phthalates trong vùng hạ lưu lưu vực Sài Gòn - Đồng Nai
}

\author{
Hoàng Thị Thanh Thủy*, Cấn Thu Văn, Nguyễn Đinh Tuấn \\ Truờng Đại học Tài nguyên và Môi trường TP. Hồ Chí Minh, \\ 236B Lê Văn Sỹ, Quận Tân Bình, TP. Hồ Chí Minh \\ Nhận ngày 08 tháng 8 năm 2016 \\ Chỉnh sửa ngày 26 tháng 8 năm 2016; Chấp nhận đăng ngày 16 tháng 12 năm 2016
}

\begin{abstract}
Tóm tắt: Hiện nay, các sản phẩm nhựa ngày càng phổ biến và được sử dụng rộng rãi trong các lĩnh vực của đời sống cũng như công nghiệp. Trong quá trình sản xuất nhựa, vai trò của các phthalate là rất quan trọng bởi chúng là các chất phụ gia làm tăng độ dẻo và bền cho các sản phẩm nhựa, đặc biệt là PVC. Một vài phthalate cũng được sử dụng như các dung môi hòa tan. Có đến hàng trăm sản phẩm có phthalate ví dụ như gạch nhựa, keo dán, chất tẩy rửa, dầu bôi trơn, nội thất ô tô, quần áo mưa và hóa mỹ phẩm (xà phòng, dầu gội, keo xịt tóc và sơn móng tay). Tuy nhiên, phthalate cũng đồng thời là các hợp chất gây rối loạn nội tiết. Sự có mặt của các phthalate, cụ thế là di 2-ethylhexyl phthalate (DEHP) có thể gây ảnh hưởng đến các hoc-môn sinh dục ở cơ thể người, đặc biệt là nam giới. Các kết quả nghiên cứu đã cho thấy DEHP gây rối loạn sinh lý biến đồi giới tính ở bé trai và gây dậy thì sớm ở các bé gái. Chính vì lý do này, DEHP nói riêng và phthalate nói chung đã và đang được các nhà khoa học quan tâm. Bài báo trình bày các kết quả nghiên cứu bước đầu về sự hiện diện của nhóm chất ô nhiễm nói trên trong vùng hạ lưu lưu vực Sài Gòn - Đồng Nai. Kết quả phân tích đã cho thấy nhóm chất gây rối loạn nội tiết phthalates có tần suất phát hiện cũng khá cao, đặc biệt trong pha rắn (trầm tích). Do đó, rất cần có các nghiên cứu chi tiết hơn về sự tồn lưu của nhóm chất ô nhiễm này trong môi trường và các rủi ro sinh thái có thể xảy ra.
\end{abstract}

Từ khóa: Chất gây rối loạn nội tiết, phthalate, lưu vực sông, nước mặt, trầm tích.

\section{Mở đầu}

Khi được sử dụng như các chất phụ gia trong công nghiệp, các phthalate (PE) không liên kết hóa học với các nguyên liệu nên có thể di chuyển từ các sản phẩm vào môi trường trong quá trình sử dụng và chôn lấp [1]. Các nghiên cứu đã cho thấy có đến $95 \%$ - 99,9\% các $\mathrm{PE}$

\footnotetext{
* Tác giả liên hệ. ĐT.: 84-983029127

Email: htthuy@hcmunre.edu.vn
}

không gắn kết với các chất dẻo và sản phẩm nên có thể phân tách từ các sản phẩm do nhiệt, phản ứng với chất lỏng và chất béo, các chất xúc tác. Sự phân tách này có thể xảy ra trong suốt vòng đời của sản phẩm từ các giai đoạn sản xuất, sử dụng và chôn lấp. Ngoài ra các $\mathrm{PE}$ cũng là thành phần của nhiều sản phẩm khác như keo dán, chất tẩy rửa, dầu bôi trơn và hóa mỹ phẩm. Do đó, các PE có mặt trong nhiều loại nguồn thải bao gồm hoạt động công nghiệp, bãi chôn lấp của các sản phẩm và chất 
thải công nghiệp, bãi chôn lấp chất thải đô thị, quá trình sử dụng bùn lắng từ trạm xử lý nước thải làm phân bón và các sản phẩm khác có chứa các PE. Sự hiện diện của các PE trong môi trường không khí, đất, nước mặt và trầm tích sông, và sinh vật do kết quả của việc sản xuất, sử dụng và chôn lấp các sản phẩm có $\mathrm{PE}$ đã được xác nhận qua nhiều nghiên cứu $[2,3]$. Nước thải là nguồn ô nhiễm chủ yếu của nhóm các $\mathrm{PE}$ trong môi trường. Các $\mathrm{PE}$ thường hiện diện trong nước rỉ rác $[4,5]$, nước thải trước và sau xử lý của các trạm xử lý nước thải, bùn thải $[6,7]$.

Hiện nay, trong danh sách "Thống kê phát thải” của Cục Bảo vệ môi trường Mỹ (EPA's Toxics Release Inventory (TRI.list)) đã có các dữ liệu của hai $\mathrm{PE}$ là $\mathrm{DBP}$ và $\mathrm{DEHP}$. Các dữ liệu liên quan cho thấy hai $\mathrm{PE}$ này có khả năng hiện diện trong tất cả các hợp phần môi trường. Dữ liệu năm 2007 đã cho thấy tải lượng phát thải của $\mathrm{DBP}$ và $\mathrm{DEHP}$ là 152 tấn từ 134 nguồn phát thải trực tiếp và 557 tấn từ 251 nguồn thải gián tiếp. Các số liệu này cũng chỉ ra rằng tải lượng phát thải của các $\mathrm{PE}$ đối với các hợp phần môi trường có thể được sắp xếp theo thứ tự giảm dần như sau: đất, không khí và nước mặt [8]. Các $\mathrm{PE}$ trong khí quyển sau khi được giải phóng có thể bị hấp thu bởi các vật thể rắn và di chuyển một khoảng cách khá xa. Trong môi trường đất và trầm tích, các PE là những chất ô nhiễm bền nên khả năng tích lũy sinh học cao. Một số PE là những chất gây rối loạn nội tiết và do đó có hại đối với quá trình sinh sản.

\section{Phương pháp nghiên cứu}

\subsection{Khảo sát hiện trạng sủ dụng các PE tại các khu công nghiệp}

Các thông tin về hiện trạng sử dụng các PE trong công nghiệp được tiến hành theo bảng câu hỏi đối với hai loại hình doanh nghiệp có thể sử dụng PE dưới dạng chất phụ gia trong quá trình sản xuất là i) sản xuất sản phẩm nhựa và ii) hóa mỹ phẩm. Số lượng doanh nghiệp khảo sát là
100 doanh nghiệp thuộc các khu công nghiệp trên địa bàn TP. HCM, tỉnh Đồng Nai và tỉnh Bình Dương.

\subsection{Khảo sát đánh giá sụ hiện diện của các PE trong vùng hạ lưu luu vưc Sài Gòn - Đồng Nai} 2.2.1. Vị trí lấy mẫu

Các vị trí lấy mẫu được lựa chọn đặc trưng cho nguồn tiếp nhận là vùng hạ lưu lưu vực Sài Gòn - Đồng Nai. Các vị trí được lựa chọn là các vị trí lấy mẫu đặc trưng cho nguồn cấp nước hoặc tiếp nhận nhiều loại nguồn thải. Mẫu được lấy theo hai thời điểm (năm 2012 và 2013). Ở mỗi vị trí đã tiến hành thu thập cả hai loại mẫu (nước mặt và trầm tích).

2.2.2. Phương pháp lấy mẫu và bảo quản mẫu

Mẫu nước được lấy trong phạm vi cách bờ khoảng $2-3 \mathrm{~m}$. Đối với mẫu trầm tích sử dụng khoan tay bằng thép. Độ sâu lấy mẫu tối đa là $40 \mathrm{~cm}$. Các chỉ tiêu dễ thay đổi theo thời gian $(\mathrm{pH}, \mathrm{DO}$, nhiệt độ) được đo tại hiện trường bằng máy đo đa thông số HQ40D (Hatch, Mỹ). Mẫu phân tích các chỉ tiêu hóa lí khác được lưu trong bình nhựa dung tích $2 \mathrm{~L}$ và gửi phân tích. Đối với các mẫu phân tích nồng độ PE được lưu trong chai thủy tinh sẫm màu dung tích $4 \mathrm{~L}$ và được bổ sung Sodium azide $\left(\mathrm{NaN}_{3}\right)$ với liều lượng $0,5 \mathrm{~g} \mathrm{NaN}_{3} / \mathrm{L}$ nước mẫu nhằm hạn chế quá trình phân hủy sinh học $[9,10]$.

\subsubsection{Phương pháp phân tích các $P E$}

Các chỉ tiêu phân tích mẫu bao gồm $6 \mathrm{PE}$ là BBP (Benzylbutylphthalate), DBP (Dibutyl phthalate), DNOP (Di-n-octyl phthalate), DEHP (Di(2-ethylhexyl) phthalate), DIDP (Diisodecyl phthalate) và DINP (Di-isononyl phthalate). Đơn vị phân tích là Công ty TNHH MTV Khoa học Công nghệ Hoàn Vũ. Phương pháp phân tích theo phương pháp chuẩn của Hiệp hội các nhà phân tích (Association of Official Analytical Chemists - AOAC 2007.01).

Mẫu nước được cho vào ống ly tâm chứa hỗn hợp $0,15 \pm 0,03 \mathrm{~g} \mathrm{MgSO}_{4}$ và $0,05 \pm 0,01 \mathrm{~g}$ bột PSA, trộn đều mẫu và sau đó ly tâm ở tốc độ 3.000 vòng/phút trong 3 phút. Dịch chiết được phân tích $\mathrm{PE}$ bằng máy sắc ký khí ghép khối phổ GC-MS/MS.

Mẫu trầm tích được thêm vào $10 \mathrm{ml}$ 
acetonitrile (1\% acid acetic) và lắc trong vòng 1 phút. Sau đó, thêm tiếp vào hỗn hợp $4 \pm 0,2 \mathrm{~g}$ $\mathrm{MgSO}_{4}$ và $1 \pm 0,05 \mathrm{~g} \mathrm{CH}_{3} \mathrm{COONa}$, trộn đều mẫu và ly tâm 3.000 vòng/phút trong 3 phút. Sau khi ly tâm, dịch chiết được tiếp tục xử lý như mẫu nước và tiêm vào máy GC-MS/MS.

Thiết bị sắc ký khí Thermo GC-MS/MS TSQ 7000 được sử dụng để xác định nồng độ các PE. Các thông số cơ bản của điều kiện vận hành như sau: (1) Cột: ZB-MR2 30m x 0,32mm x $0,25 \mu \mathrm{m}$; (2) Khí mang: Helium với tốc độ dòng $1,7 \mathrm{ml} /$ phút; (3) Nhiệt độ bộ phận tiêm mẫu: $300^{\circ} \mathrm{C}$.

Giới hạn phát hiện (LOD) đối với các $\mathrm{PE}$ theo các chỉ tiêu BBP, DBP, DNOP, DEHP, DIDP và $\mathrm{DINP}$ bằng phương pháp $\mathrm{AOAC}$ 2007.01 là $2 \mu \mathrm{g} / \mathrm{l}$ và $0,01 \mathrm{mg} / \mathrm{kg}$.

\section{Kết quả và thảo luận}

Các kết quả xử lý thống kê về dư lượng nhóm các $\mathrm{PE}$ trong vùng nghiên cứu được tổng hợp tại Bảng 1. Dư lượng các PE ở vùng hạ lưu sông Đồng Nai nhìn chung cao hơn so với sông Sài Gòn.

\subsection{Sông Đồng Nai}

Trong các mẫu nước của vùng hạ lưu sông Đồng Nai, DEHP có tần suất cao nhất (4/11 vị trí) tiếp theo là DBP và DINP (một vị trí duy nhất) và ba $\mathrm{PE}$ khác (BBP, DNOP và DIDP) đều không phát hiện được. Dư lượng của DEHP biến thiên khá lớn, thay đổi từ $9-53$ $\mu \mathrm{g} / \mathrm{L}$. Nhưng xu thế của nhóm các $P E$ là tích lũy chủ yếu trong pha rắn (trầm tích). Hầu hết tất cả các mẫu trầm tích đều phát hiện dư lượng của DEHP (8/11 mẫu) và DINP (7/11 mầu) (Bảng 3 ). DIDP và DBP có cùng tần suất xuất hiện là 4/11 mẫu. BBP chỉ xuất hiện tại một vị trí duy nhất.

Tại khu vực lân cận trạm bơm Hóa An đã tiến hành khảo sát tại hai vị trí DN-HA1 và DH-HA2. Dư lượng DEHP đã phát hiện được trong cả hai đợt khảo sát 2012 và 2013 (3/4 mẫu). Tuy nhiên, một điểm cần lưu ý là dư lượng DEHP trong mẫu nước mùa khô 2013 (DN-HA1 và DN-HA2: 9-25 $\mu \mathrm{g} / \mathrm{L}$ ) đã giảm hơn nhiều trong năm 2012 (DN-HA1: $53 \mu \mathrm{g} / \mathrm{L}$ ). Nhưng dư lượng DEHP vẫn hiện diện ở mức độ khá cao và thường xuyên trong mẫu trầm tích của vị trí này $(1,48-2,66 \mathrm{mg} / \mathrm{kg})$. Do đó, có thể đánh giá rằng tuy dư lượng trong pha nước giảm nhưng dư lượng trong trầm tích lại tăng nên rủi ro của DEHP tại khu vực này vẫn cần được xem xét. Bên cạnh đó, tại vị trí $\mathrm{DN}$ HA1 cũng đã phát hiện dư lượng khá cao của các PE khác trong cả hai loại mẫu nước mặt và trầm tích: DBP trong mẫu nước $51 \mu \mathrm{g} / \mathrm{L}$, $\mathrm{BBP}$ và $\mathrm{DBP}$ trong mẫu trầm tích lần lượt là 0,25 và $0,09 \mathrm{mg} / \mathrm{kg}$ và của đợt khảo sát mùa mưa năm 2012. Tại vị trí DN-HA2 tuy không phát hiện dư lượng trong mẫu nước nhưng đã phát hiện dư lượng của DBP, DEHP, DIDP và DINP khá phổ biến trong trầm tích, đặc biệt tại thời điểm mùa khô, tháng 4/2013. Do đó, tại khu vực này rất cần lưu ý về sự hiện diện của dư lượng các $\mathrm{PE}$.

Tại vị trí lân cận trạm bơm của Nhà máy nước Biên Hòa cũng phát hiện dư lượng DEHP tại thời điểm khảo sát mùa khô 2013, trong khi đó cũng tại vị trí này trong đợt khảo sát mùa mưa 2012 đã không phát hiện dư lượng DEHP. Bên cạnh đó, vị trí này cũng là vị trí duy nhất đã phát hiện dư lượng DINP duy nhất trong tổng số 11 mẫu nước của sông Đồng Nai. Tương tự như tại khu vực lân cận Trạm bơm Hóa An, dư lượng các PE trong trầm tích ở khu vực lân cận Nhà máy nước Biên Hòa cũng xuất hiện khá phổ biến và hàm lượng thậm chí còn cao hơn cả khu vực Trạm bơm Hóa An. Ví dụ như hàm lượng $\mathrm{DEHP}$ tại hai vị trí $\mathrm{DN}-\mathrm{BH} 1$ và $\mathrm{DN}-\mathrm{BH} 2$ đã lên tới 135 và $102 \mathrm{mg} / \mathrm{kg}$. Tuy nhiên, tại đợt khảo sát tháng $8 / 2013$, nồng độ DEHP ở vị trí DN-HB2 đã giảm xuống chỉ còn $0,7 \mathrm{mg} / \mathrm{kg}$.

Tại khu vực phà Cát Lái, xu thế tích lũy trong pha rắn của các $\mathrm{PE}$ cũng được thể hiện rõ khi chỉ phát hiện dư lượng DEHP và DINP trong mẫu trầm tích $(2,18$ và $0,22 \mathrm{mg} / \mathrm{kg})$ còn các mẫu nước thì nồng độ các $\mathrm{PE}$ đều nhỏ hơn LOD. 


\subsection{Sông Sài Gòn}

Trong các mẫu nước của sông Sài Gòn chỉ phát hiện được DEHP ở một vị trí duy nhất ở hạ lưu cầu An Hạ vào thời điểm tháng 4/2013. Ngoài ra năm $\mathrm{PE}$ khác đều không phát hiện được (BBP, DBP, DNOP, DIDP và DINP). Tuy nhiên, trong mẫu trầm tích, tần suất xuất hiện của các $\mathrm{PE}$ thường xuyên hơn. DEHP vẫn được phát hiện nhiều nhất (7/12 mẫu), tiếp theo là DINP (3/12 mẫu) (Bảng 1). BBP và DIDP chỉ phát hiện được duy nhất tại một vị trí và tương tự như sông Đồng Nai, DNOP không phát hiện được trong số tất cả 12 mẫu phân tích.

Bảng 1. Kết quả nghiên cứu dư lượng các $\mathrm{PE}$ tại vùng hạ lưu lưu vực Sài Gòn - Đồng Nai

\begin{tabular}{|c|c|c|c|c|c|c|c|c|c|c|c|c|}
\hline & \multicolumn{6}{|c|}{ Mẫu nước ( $\mu \mathrm{g} / \mathrm{l})$} & \multicolumn{6}{|c|}{ Mẫu bùn (mg/kg) } \\
\hline & BBP & DBP & DNOP & DEHP & DIDP & DINP & BBP & DBP & DNOP & DEHP & DIDP & DINP \\
\hline \multicolumn{13}{|l|}{$\begin{array}{l}\text { Khu vực } \\
\text { nghiên cứu }\end{array}$} \\
\hline $\max$ & & 51 & & 53 & 0 & 2,2 & 0,28 & 0,19 & & 135 & 1,0 & 3,2 \\
\hline $\min$ & & & & 9 & 0 & & 0,25 & 0,04 & & 0,26 & 0,08 & 0,05 \\
\hline TB & & & & 27 & & & 0,27 & 0,13 & & 17 & 0,54 & 0,71 \\
\hline $\begin{array}{l}\text { Độ lệch } \\
\text { chuẩn }\end{array}$ & & & & 17 & & & 0,02 & 0,07 & & 41 & 0,43 & 1,1 \\
\hline $\begin{array}{l}\text { Tần suất xuất } \\
\text { hiện (mẫu) }\end{array}$ & 0 & 1 & 0 & 5 & 0 & 1 & 2 & 4 & 0 & 15 & 5 & 10 \\
\hline $\begin{array}{l}\text { Tần suất xuất } \\
\text { hiện }(\%)\end{array}$ & - & 4 & & 22 & - & 4 & 9 & 17 & - & 65 & 22 & 43 \\
\hline \multicolumn{13}{|l|}{$\begin{array}{l}\text { Sông Đồng } \\
\text { Nai }\end{array}$} \\
\hline $\max$ & & 51 & & 53 & & 2,2 & 0,25 & 0,19 & & 135 & 1,01 & 3,21 \\
\hline $\min$ & & & & 9 & & & & 0,04 & & 0,7 & 0,08 & 0,14 \\
\hline ТВ & & & & 25 & & & & 0,13 & & 31 & 0,63 & 0,96 \\
\hline $\begin{array}{l}\text { Độ lệch } \\
\text { chuẩn }\end{array}$ & & & & 20 & & & & 0,07 & & 55 & 0,44 & 1,24 \\
\hline $\begin{array}{l}\text { Tần suất xuất } \\
\text { hiện (mẫu) }\end{array}$ & 0 & 1 & 0 & 4 & 0 & 1 & 1 & 4 & 0 & 8 & 4 & 7 \\
\hline $\begin{array}{l}\text { Tần suất xuất } \\
\text { hiện }(\%)\end{array}$ & - & 9 & - & 17 & - & 9 & 9 & 36 & - & 72 & 36 & 63 \\
\hline \multicolumn{13}{|l|}{$\begin{array}{l}\text { Sông Sài } \\
\text { Gòn }\end{array}$} \\
\hline $\max$ & & & & 33 & & & 0,28 & & & 2,0 & 0,20 & 0,20 \\
\hline $\min$ & & & & & & & & & & 0,26 & 0,20 & 0,05 \\
\hline $\mathrm{TB}$ & & & & & & & & & & 0,73 & 0,20 & 0,12 \\
\hline $\begin{array}{l}\text { Độ lệch } \\
\text { chuẩn }\end{array}$ & & & & & & & & & & 0,64 & & 0,08 \\
\hline $\begin{array}{l}\text { Tần suất xuất } \\
\text { hiện (mẫu) }\end{array}$ & 0 & 0 & 0 & 1 & 0 & 0 & 1 & 0 & 0 & 7 & 1 & 3 \\
\hline $\begin{array}{l}\text { Tần suất xuất } \\
\text { hiện }(\%)\end{array}$ & - & - & - & 8 & - & - & 8 & - & - & 58 & 8 & 25 \\
\hline
\end{tabular}

Ghi chú: Các giá trị thống kê chỉ tính trên các mẫu có nồng độ > LOD; max; giá trị lớn nhất, min: giá trị nhỏ nhất, TB: giá trị trung bình số học. 
Tại khu vực lân cận trạm bơm Hòa Phú chỉ phát hiện được dư lượng của $\mathrm{BBP}, \mathrm{DEHP}$ và DIDP trong mẫu trầm tích của đợt khảo sát tháng 10/2012. Ở đợt khảo sát tháng 4/2013 thì dư lượng DEHP đã giảm và < LOD.

Tương tự, tại khu vực Bến đò Bình Mỹ cũng chỉ phát hiện dư lượng DEHP trong mẫu trầm tích của đợt khảo sát tháng 10/2012. Còn trong mẫu nước và mẫu trầm tích của đợt khảo sát tháng 10/2013 dư lượng của DEHP đều < LOD.

Tại khu vực cầu An Hạ các kết quả phân tích cho thấy diễn biến khá phức tạp của các PE. Trong các mẫu nước chỉ phát hiện được duy nhất dư lượng của DEHP tại vị trí duy nhất là hạ lưu cầu An Hạ (SG-AH2: $33 \mu \mathrm{g} / \mathrm{L}$ ). Tuy nhiên, trong các mẫu trầm tích thì sự xuất hiện của DEHP khá thường xuyên hơn với $3 / 4$ mẫu phân tích. Dư lượng DEHP thay đổi từ $0,31-$ $2,02 \mathrm{mg} / \mathrm{kg}$. Tại chân cầu An Hạ chỉ phát hiện được dư lượng DEHP tại thời điểm tháng 10/2012, sang đến tháng 4 năm 2013 thì tại vị trí này dư lượng DEHP< LOD. Tuy nhiên, ở hai vị trí thượng lưu và hạ lưu của cầu $A n$ Hạ đều xác định được dư lượng DEHP (SG-AH2: 0,31 $\mathrm{mg} / \mathrm{kg}$ và $\mathrm{SG}-\mathrm{AH} 3: 0,38 \mathrm{mg} / \mathrm{kg}$ ). Điều này cho thấy sự hiện diện của các $\mathrm{PE}$ nói chung và DEHP nói riêng trong các mẫu môi trường rất khó xác định và phụ thuộc rất nhiều vào các yếu tố khách quan (lấy mẫu, bảo quản mẫu, phân tích, v.v). Bên cạnh DEHP, thời điểm tháng 10/2012 tại vị trí cầu An Hạ là vị trí duy nhất đã phát hiện được dư lượng DINP. Dư lượng các PE khác đều nhỏ hơn giới hạn phát hiện trong cả hai đợt khảo sát. Do tần suất xuất hiện khá phổ biến của DEHP tại khu vực cầu An Hạ nên có thể khẳng định sự hiện diện của chất ô nhiễm này.

Tại khu vực Thủ Thiêm, cũng đã phát hiện được dư lượng của DEHP $(0,74 \mathrm{mg} / \mathrm{kg})$ và DINP $(0,12 \mathrm{mg} / \mathrm{kg})$ trong mẫu trầm tích tại thời điểm khảo sát tháng 11/2013. Tuy nhiên, tại thời điểm mùa khô (tháng 4/2013) thì dư lượng của các $\mathrm{PE}$ này đều nhỏ hơn giới hạn phát hiện. Đối với mẫu nước thì dư lượng các PE đều nhỏ hơn giới hạn phát hiện trong cả hai đợt khảo sát.
Tương tự, tại khu vực Bình Khánh cũng đã phát hiện được dư lượng của DEHP và DINP tại thời điểm khảo sát tháng 11/2013 nhưng nồng độ thấp hơn so với khu vực Thủ Thiêm (DEHP: $0,26 \mathrm{mg} / \mathrm{kg}$ và DINP: $0,05 \mathrm{mg} / \mathrm{kg}$ ). Tại thời điểm mùa khô (tháng 4/2013) thì dư lượng của các $\mathrm{PE}$ này đều nhỏ hơn giới hạn phát hiện. Đối với mẫu nước thì dư lượng các $\mathrm{PE}$ đều nhỏ hơn giới hạn phát hiện trong cả hai đợt khảo sát.

\subsection{Thảo luận}

Nhìn chung các $\mathrm{PE}$ thường gặp ở khu vực nghiên cứu bao gồm $\mathrm{DEHP}$ và $\mathrm{BBP}, \mathrm{DBP}$, DIDP, DINP. Trong đó, đáng lưu ý DEHP là một chất có thể gây rối loạn nội tiết đã xuất hiện khá phổ biến trong trầm tích. Độ lệch chuẩn cũng cao hơn hẳn giá trị trung bình của DEHP cho thấy có sự biển thiên khá lớn giữa các vị trí khảo sát. Điều này cũng thể hiện tác động của các nguồn thải nhân sinh đối với các nồng độ tự nhiên của lưu vực. Còn các PE khác thể hiện mức dư lượng và độ lệch chuẩn khá thấp, và có thể chủ yếu là giá trị nền.

Sự biến thiên theo thời gian của các $P E$ cũng không rõ rệt giữa hai thời điểm lấy mẫu. Ngay cả tại vị trí lân cận Nhà máy nước Biên Hòa, nơi đã phát hiện dư lượng DEHP rất cao trong trầm tích cũng chỉ mang tính chất thời điểm.

Theo chiều dòng chảy từ thượng lưu đến hạ lưu của cả hai sông Sài Gòn và Đồng Nai đều không thể hiện xu thế rõ rệt. Nguyên nhân có thể do đây là một nghiên cứu bước đầu, nên số lượng vị trí lấy mẫu và độ lặp còn thấp.

Mặc dù số lượng vị trí khảo sát và tần suất lấy mẫu còn hạn chế nhưng kết quả nghiên cứu của đề tài cũng đã bước đầu cho thấy có sự hiện diện của các $P E$ tại vùng hạ lưu lưu vực Sài Gòn - Đồng Nai. Nguồn thải chủ yếu của các PE ở khu vực nghiên cứu có thể bao gồm nước thải có dư lượng các $\mathrm{PE}$ tồn lưu trong suốt vòng đời của các sản phẩm $\mathrm{PVC}$ hoặc các sản phẩm khác như hóa mỹ phẩm, mực in,...

Với một ngoại lệ là dư lượng DNOP rất thấp và nhỏ hơn $\mathrm{LOD}$ trong tất cả các mẫu phân tích, 
các $\mathrm{PE}$ khác (BBP, DBP, DEHP, DIDP và DINP) đều thể hiện xu thế tích lũy trong trầm tích. Nguyên nhân là do bên cạnh hệ số tan thấp thì các $\mathrm{PE}$ có hệ số Kow cao nên một lần nữa thể hiện tính chất kỵ nước và có xu thế tích lũy trong pha rắn (sinh vật, trầm tích) cao hơn trong pha lỏng. Hệ số Kow tăng cùng với chiều dài của chuỗi alkyl và do đó các $\mathrm{PE}$ có trọng lượng phân tử lớn (DEHP, DIDP, DINP) sẽ ít tan hơn và do đó dư lượng của các $P E$ này đều cao hơn các $\mathrm{PE}$ có trọng lượng phân tử thấp (BBP, DBP). Mặt khác, quá trình phân hủy sinh học có thể là quá trình phân hủy chủ yếu và đã làm giảm dư lượng của các $\mathrm{PE}$ trong môi trường nước [11]. Các nghiên cứu của hai nhóm tác tả Cartwright và Yuan đã cho thấy các $\mathrm{PE}$ với trọng lượng phân tử thấp như BBP, DBP đều phân hủy khá nhanh trong đất và trầm tích hiếu khí và do đó là các chất ô nhiễm kém bền - có thể tính chất này cũng tương tự như trong môi trường nước $[12,13]$. Có lẽ chính vì vậy, dư lượng của các $\mathrm{PE}$ này khá thấp trong trầm tích.

Đặc biệt nghiêm trọng, DEHP - một các PE cần quan tâm nhiều nhât do đã được xếp vào danh sách các chất có thể gây rối loạn nội tiết đã được phát hiện có dư lượng và tần suất xuất hiện cao nhất tại khu vực nghiên cứu. Nguyên nhân có thể do chất phụ gia này được sử dụng rộng rãi trong công nghiệp. Đồng thời các sản phẩm có chứa DEHP cũng đang được sử dụng thường xuyên cũng có thể là nguyên nhân dẫn đến sự phân tách các DEHP từ sản phẩm và hiện diện trong nước thải sinh hoạt và từ đó di chuyển đến lưu vực Sài Gòn - Đồng Nai. Bên cạnh đó, do có hệ số tan rất thấp, có tính kị nước nên trầm tích là môi trường tích lũy của DEHP và chất ô nhiễm này có thể tồn lưu trong trầm tích một thời gian dài.

Tóm lại, dư lượng của nhóm chất các $\mathrm{PE}$ ở dạng hòa tan trong nước tại vùng hạ lưu lưu vực Sài Gòn - Đồng Nai còn khá thấp. Nhưng các $\mathrm{PE}$ này chủ yếu tích lũy trong trầm tích của sông Sài Gòn và sông Đồng Nai. Do $\mathrm{PE}$ là các chất có thể gây rối loạn nội tiết nên sự hiện diện của dư lượng các chất này trong vùng hạ lưu lưu vực Sài Gòn - Đồng Nai cần được quan trắc định kỳ để có thể xác định chính xác sự hiện diện của nhóm chất ô nhiềmm này.

\section{Kết luận}

Lần đầu tiên, các nghiên cứu liên quan đến chất ô nhiễm gây rối loạn nội tiết DEHP và các $\mathrm{PE}$ đã được triển khai. Với số lượng mẫu còn hạn chế nên kết quả nghiên cứu của đề tài chỉ là những khảo sát sơ bộ ban đầu để khẳng định sự tồn lưu của các chất ô nhiễm PE tại khu vực hạ lưu lưu vực Sài Gòn - Đồng Nai. Tuy nhiên, từ các kết quả của đề tài cũng đã cho thấy trong thời gian tới cần có các nghiên cứu chi tiết và đầy đủ hơn về sự tồn lưu của các PE trong các hợp phần môi trường (không khí - đất - nước mặt/trầm tích - sinh vật) để có thể có các kết luận chính xác về nguồn gốc, sự chuyển hóa và tác động tiêu cực có thể có của nhóm chất ô nhiễm này.

\section{Lời cảm ơn}

Bài báo hoàn thành dựa trên kết quả của đề tài nghiên cứu khoa học và phát triển công nghệ cấp Bộ Tài nguyên và Môi trường, TNMT.04.30, đơn vị chủ trì: Trường Đại học Tài nguyên và Môi trường TP.HCM, chủ nhiệm đề tài: PGS.TS. Nguyễn Đinh Tuấn, thời gian thực hiện 2012-2014.

\section{Tài liệu tham khảo}

[1] Cadogan D. F., Papez M., Poppe A. C., Pugh D. M. and Scheubel J. - An assessment of the release, occurrence and possible effects of plasticizers in the environment. Prog. Rubber. Plastics Technol. 10 (1993) 1-19.

[2] Wensing M., Uhde E. and Salthammer T. Plastics additives in the indoor environment flame retardants and plasticizers. Sci. Total. Environ. 339(1-3) (2005) 19 - 40.

[3] Mackintosh C.E., Maldonado J., Hongwu J., Hoover N., Chong A., Ikonomou M.G. and Gobas F.A.P.C. - Distribution of phthalate esters in a marine aquatic food web: comparison to 
polychlorinated biphenyls. Environ. Sci. Technol. 38 (2004) 2011-2020.

[4] Schwarzbauer J., Heim. S, Brinker S. and Littke R. - Occurrence and alteration of organic contaminants in seepage and leakage water from a waste deposit landfill. Water Res. 36 (2002) 2275-2287.

[5] Zheng Z., He P-J, Shao L-M and Lee D-J Phthalic acid esters in dissolved fractions of landfill leachates. Water Res. 41 (2007) 4696 -4702 .

[6] Marttinen S. K., Kettunen R. H., Sormunen K. M. and Rintala J. A. - Removal of bis(2-ethylhexyl) phthalate at a sewage treatment plant. Water Res. 37 (2003) 1385 - 1393

[7] Roslev P., Vorkamp K., Aarup J., Frederiksen K. and Nielsen P. H. - Degradation of phthalate esters in an activated sludge wastewater treatment plant. Water Res. 41 (2007) 969 - 976

[8] EPA. 2009. U.S. Environmental Protection Agency. Toxics Release Inventory (TRI) Program: Get TRI Data and Tools. 2007 Public
Data Release, Released March 14, 2009. http://www.epa.gov/tri/tridata/index.htm\#pdr.

[9] Land \& Water Autralia. Endocrine Disrupting Chemicals in the Australian Riverine Environment. http://npsi.gov.au/files/products/innovation/pr071 403/pr071403.pdf.

[10] Fromme H., Küchler T., Otto T. , Pilz K., Müller J. , Wenzel A. - Occurrence of phthalates and bisphenol $\mathrm{A}$ and $\mathrm{F}$ in the environment. Water Res. 36 (2002) $1429-1438$.

[11] Staples C.A. (editor) - The handbook of environmental chemistry. Phthalate esters, Springer, Berlin, (2003) pp. 85 - 124.

[12] Cartwright C. D., Thompson I. P. and Burns R. G. - Degradation and impact of phthalate plasticizers on soil microbial communities. Environ. Toxicol. Chem. 19 (2002) 1253-1261.

[13] Yuan S. Y., Liu C., Liao C. S. and Chang B. V. Occurrence and microbial degradation of phthalate esters in Taiwan river sediments. Chemosphere 49 (10) (2002) 1295-1299.

\title{
Study on The Occurrence of Phlathates in Downstream Area of Sai Gon - Dong Nai River Basin
}

\author{
Hoang Thi Thanh Thuy, Can Thu Van, Nguyen Dinh Tuan \\ Ho Chi Minh City University of Natural Resources and Environment, \\ 236B Le Van Sy, Ward 1, Tan Binh Dist. Ho Chi Minh City
}

\begin{abstract}
Phthalates are a group of chemicals used as plasticizers, which provide flexibility and durability to plastics such as polyvinyl chloride (PVC). Some phthalates are used as solvents (dissolving agents) for other materials. They are used in hundreds of products, such as vinyl flooring, adhesives, detergents, lubricating oils, automotive plastics, plastic clothes (rain coat), and personalcare products (soap, shampoo, hair spray, and nail polish). However, phthalates are synthetic endocrine-disrupting chemicals. Previous studies have linked prenatal exposure to phthalates (DEHP) to male reproductive system abnormalities, sexual developments of boys and girls. The paper reported the primarily study on the occurrence of phthalates in the of Saigon - Dongnai river basin. The analytical results have showed the residues of those contaminants in aquatic system. Phthalates were detected both in water and sediment. Thus, a more detailed study is necessary to identify the occurrence and fate as well as ecological risks of those contaminants in aquatic system.
\end{abstract}

Keywords: Endocrine disruptor, phthalate, river basin, water, sediment. 